\title{
Materials for Electrocatalysis of Oxygen Evolution in PEM Water Electrolysis Cells
}

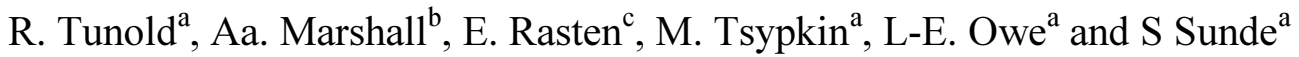 \\ ${ }^{\mathrm{a}}$ Group of Electrochemistry, Department of Materials Science and Engineering, NTNU, \\ NO7491 Trondheim Norway \\ ${ }^{\mathrm{b}}$ present address. University of Canterbury, Canterbury, New Zealand \\ ${ }^{c}$ present address: INEOS, Herøya Research Park, NO 3908 Porsgrunn, Norway
}

\begin{abstract}
Proton exchange membrane (PEM) water electrolysis offers several advantages compared to the traditional alkaline technologies including higher energy efficiencies, considerably higher specific production rates leading to more compact design, and avoiding a liquid and highly corrosive electrolyte. The oxygen electrode is the critical part in the energy consumption of such cells. To obtain high performance, electrocatalytically very active anode materials have to be developed for the oxygen evolving interface. The most promising electrocatalytic materials are based on $\mathrm{IrO}_{2}$ and $\mathrm{RuO}_{2}$, preferably in mixtures with other transition metal oxides with electronic conductivity. Excellent performance has been obtained by using nanocrystalline electrocatalysts based on iridium oxide with additions of ruthenium oxide and/or tin oxide, forming rutile structures, or mixed with tantalum pentoxide. This concept has been applied extensively in our work and has been successful in understanding oxygen evolution performance variations in $\mathrm{IrO}_{2}-\mathrm{RuO}_{2}, \mathrm{IrO}_{2}-\mathrm{SnO}_{2}$, IrO $\mathrm{IO}_{2}-\mathrm{RuO}_{2}-\mathrm{SnO}_{2}$ and $\mathrm{IrO}_{2}-\mathrm{RuO}_{2}-$ $\mathrm{Ta}_{2} \mathrm{O}_{5}$ systems.
\end{abstract}

\section{Hydrogen in a future energy conversion system}

Hydrogen is believed to become a major energy carrier in the future, besides electrons, especially for transport purposes and for intermediate storage of renewable energy. Hydrogen may then be transformed to power by electrochemical energy conversion in fuel cells - DCpower or by internal combustion

Water electrolysis is the most feasible method for hydrogen production from renewable energy sources like wind- and sun-power. Increased energy and volume efficiency of water electrolysis systems is of great importance. PEM water electrolysis uses technology similar to PEM fuel cells. The Oxygen anode is the main potential controlling part. Noble metal oxides show high activity for oxygen evolution in PEM water electrolysis systems with the following electrode processes.

$$
\begin{array}{ll}
\text { Cathode: } & 4 \mathrm{H}^{+}+4 \mathrm{e}^{-} \rightarrow 2 \mathrm{H}_{2} \\
\text { Anode: } & 2 \mathrm{H}_{2} \mathrm{O} \rightarrow \mathrm{O}_{2}+4 \mathrm{H}^{+}+4 \mathrm{e}^{-} \\
\text {Total: } & 2 \mathrm{H}_{2} \mathrm{O} \rightarrow \mathrm{O}_{2}+2 \mathrm{H}_{2}
\end{array}
$$

High performance is achieved using PEM cells. In alkaline cells $0.2 \mathrm{~A} / \mathrm{cm}^{2}$ is obtained at 1.7-2.0 V. In polymer cells a cd of $1 \mathrm{~A} / \mathrm{cm}^{2}$ is obtained at $1.6-1.7 \mathrm{~V}$ and current densities of $3-5 \mathrm{~A} / \mathrm{cm}^{2}$ are possible without excessive voltages in such systems. This is due to very low overpotentials and ohmic resistances and low transport resistances. In addition one obtains: 
- $\quad$ No liquid electrolyte complications

- $\quad$ Very pure $\mathrm{H}_{2}$ and $\mathrm{O}_{2}$ produced

- Gas separation simple

- $\quad$ Pressurisation, up to 100 bar easily accepted

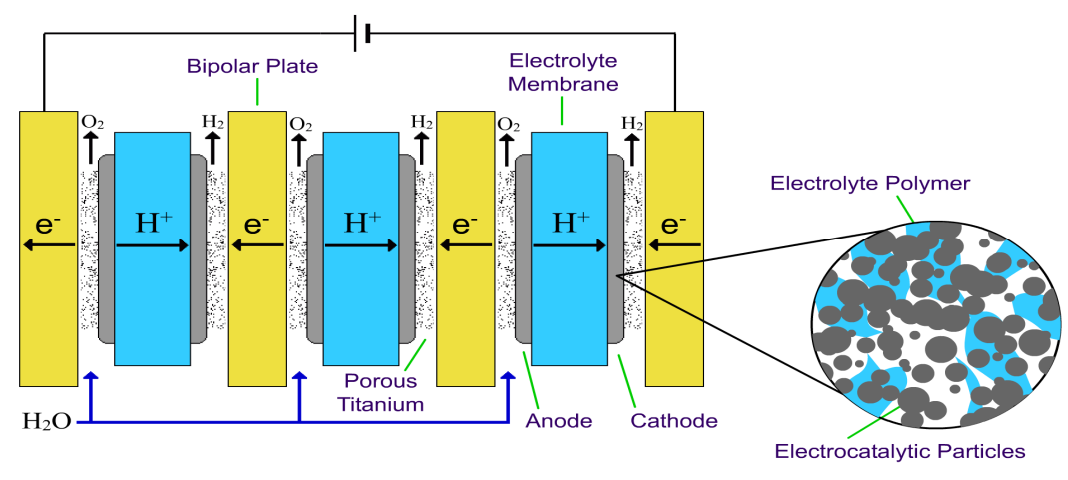

Fig. 1 Polymer Membrane Water Electrolysis Cell

\section{Critical issues for research, development of oxygen evolution catalyst}

As Hydrogen cathode catalyst Pt is the natural choice. Very low overpotentials at low and medium cds are observed. At decreased loading below $0.5 \mathrm{mg} \mathrm{cm}^{-2}$, lateral resistances in the active layer/support are observed at cds somewhere between 0.5 an $1.0 \mathrm{~A} \mathrm{~cm}^{-2}$.

The Oxygen electrode is the main factor determining the energy efficiency. For the oxygen anode, oxides of noble metals, especially Ir and Ru mixed with non-noble metal oxides of Sn, Ta and Ti are used, based on knowledge from DSA-technology (1). Actual problems: are catalytic activity and electric conductivity related to composition and loading, and stability related to crystal growth and corrosion. In our studies we have chosen $\mathrm{IrO}_{2}$ as the base material with additions of $\mathrm{RuO}_{2}$ for increased activity and $\mathrm{SnO}_{2}$ and to a certain degree $\mathrm{Ta}_{2} \mathrm{O}_{5}$ and $\mathrm{TiO}_{2}$, for increased stability.

\section{Mechanisms and Electrocatalysis}

The oxygen evolution probably starts with a surface site $\mathrm{S}$ which is covered by OH-groups in the primary step:

1. $\mathrm{S}+\mathrm{H}_{2} \mathrm{O}->\mathrm{S}-\mathrm{OH}+\mathrm{H}^{+}+\mathrm{e}^{-} \quad \mathrm{EC}$

followed either by the oxide path:

2a. $2 \mathrm{~S}-\mathrm{OH}->\mathrm{S}-\mathrm{O}+\mathrm{S}+\mathrm{H}_{2} \mathrm{O} \quad \mathrm{C}$

or the $\mathrm{S}-\mathrm{OH}$ species are oxidized to an intermediate with higher valency

the electrochemical oxide path:

2b. $\mathrm{S}-\mathrm{OH}->\mathrm{S}-\mathrm{O}+\mathrm{H}^{+}+\mathrm{e}^{-} \quad \mathrm{EC}$

Two unstable S-O then combine:

3. $2 \mathrm{~S}-\mathrm{O}->\mathrm{O}_{2}+2 \mathrm{~S} \quad \mathrm{C}$

The activity of oxidic catalyst correlates to the ability to switch between valence states in the potential range of the oxygen evolution process. 
The socalled Vulcano plots were proposed by Trasatti (2) based on measured overpotentials of the oxygen electrode vs the change of enthalpy for valence changes in the oxide and reflects the activation energy of the process and the exchange cd. The same type of diagrams were calculated by Rossmeissl and Nørskov using DFT-calculations (3) obtaining comparable results. Both groups placed Ir-oxide and Ru-oxide on top for oxygen evolution.

From a mechanistic point of view it is very important that the first charge transfer reaction is not rate determining but rather fast because of its high Tafel gradient $120-150 \mathrm{mV} / \mathrm{decade}$. At high current densities the mechanism is as important as the exchange cd. This means that the S-OH group should be rather stable. The enthalpy of formation of higher valent from lower valent oxide should have an average value - not too high - not too low. The second chemical step 2a) has a Tafel gradient of about $30 \mathrm{mV} /$ decade and upwards, depending on the temperature, whereas the electrochemical oxide path has a value of around $40 \mathrm{mV} / \mathrm{dec}$ de if the charge transfer coefficient is 0.5 . At a cd 5 decades higher than the exchange cd and a difference in Tafel gradient of $100 \mathrm{mv} /$ decade, this amounts to a difference of $0.5 \mathrm{~V}$ at the same cd.

\section{Experimental}

Production of catalysts and catalytic interfaces

Catalysts were produced by different methods:

- Pyrolysis method using nitrate melt (Adams fusion) (4-6)

- Oxidation of precursors with molten $\mathrm{NaNO}_{3}$

- $\quad$ Modified polyol procedure (7-9)

- Precursors reduced to metallic colloids in ethylene glycol at elevated

- temperatures

- Annealing forming surface oxide at typically $400-550^{\circ} \mathrm{C}$

- Aqueous hydrolysis (10)

- Ligand exchange in alkaline solution

- Oxidation by nitric acid forming surface hydroxide

- Annealing

Adams fusion could results in two separate phases for binary or ternary systems.

The polyol method was used for most of the catalyst research. Products from both the polyol and the hydrolysis processes were heat treated to $\mathrm{MO}_{\mathrm{X}}$

Particle sizes and structures obtained were:

- Polyol: 2-5 nm, amorphous and partly metallic

- Hydrolysis: 15-20 nm, oxide-hydroxide partly crystalline

MEAs were produced by spraying of ink made from powders directly onto Nafion ${ }^{\circledR}$ membrane or to a $\mathrm{Ti}$ substrate. The Ti-based electrodes were used for separate anodic measurements in $\mathrm{H}_{2} \mathrm{SO}_{4}$-solution.

\section{Results and Discussion}

Effect of heat treatment on interfacial area, catalytic activity and resistance of catalyst layer A very important aspect of electrocatalyst development and characterisation is the separation of the effect of surface area and specific activity. The active area, defined as the "outer" area was determined by extrapolating voltammetrically determined oxidic charge to infinite sweep rate (11) from voltammograms like in Fig 1. Capacitance from this charge for single $\mathrm{IrO}_{2}$, found by voltammetry, decreased by increasing heat treatment temperature, from $283 \mathrm{mF} \cdot \mathrm{cm}^{-2}$ for pristine, not heat treated, to $66 \mathrm{mF} \cdot \mathrm{cm}^{-2}$ for material treated at $540^{\circ} \mathrm{C}(5)$. 


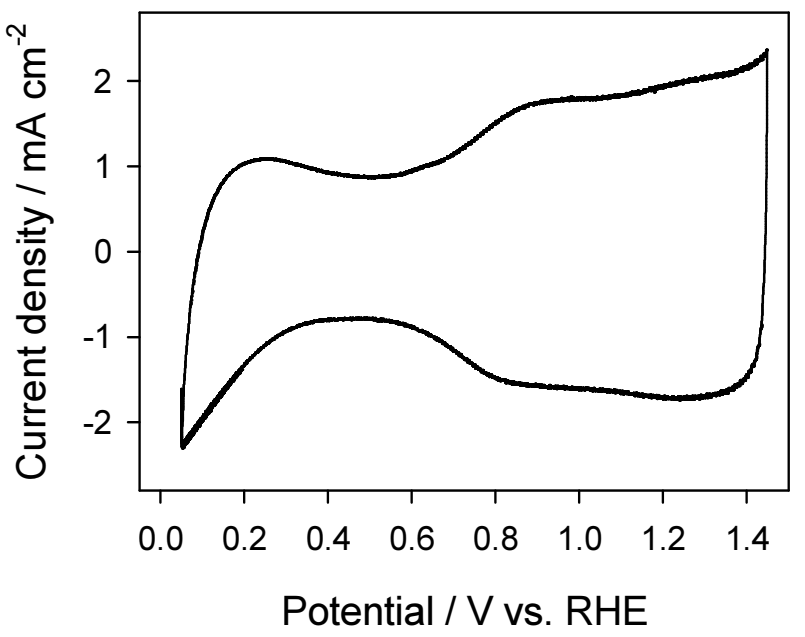

Fig. 2. $\mathrm{CV}$ of $\mathrm{IrO}_{\mathrm{x}}$ in $0.5 \mathrm{M} \mathrm{H}_{2} \mathrm{SO}_{4}$

AC-impedance revealed increasing conductance but decreasing catalytic activity by increasing temperature, as shown in Fig. 2. The optimum heat treatment temperature of this specific catalyst seemed to be $490^{\circ} \mathrm{C}$. (From ref. 5)

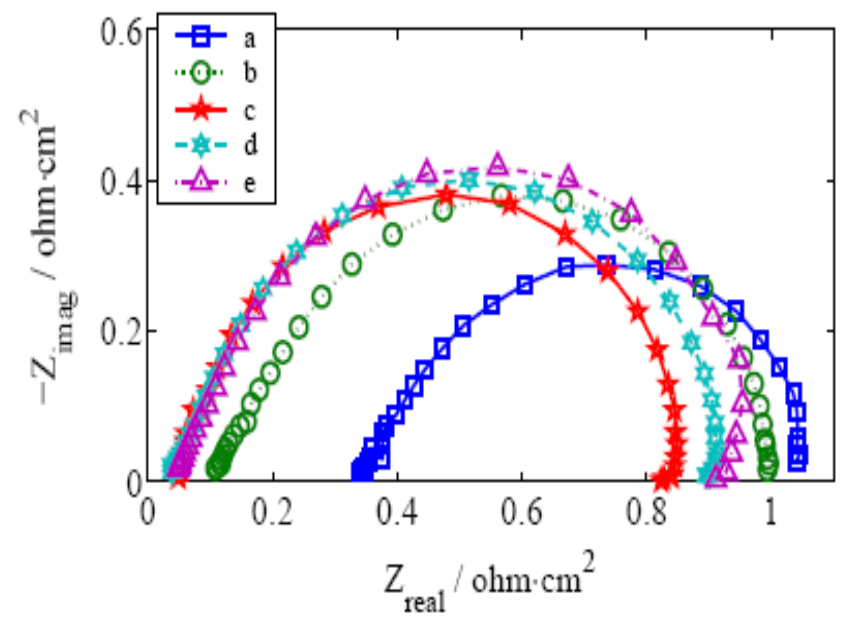

Fig.3 AC-Impedance of $\mathrm{IrO}_{2}$ catalyst as $\mathrm{f}$ (annealing temperature ${ }^{\circ} \mathrm{C}$ )

a) not annealed , b) 440, c) 490, d) 510, e) 540

Electronic properties of $\mathrm{IrO}_{2}$

The electrode capacity is very high for non annealed material and is reduced by one order of magnitude when annealed at $490^{\circ} \mathrm{C}$ as shown in Fig. 3. This could be due to a combined effect of increasing particle size and changes in the electronic conduction mode. The non annealed material appears to have semiconducting properties with p-type conduction up to $1.55 \mathrm{~V}$ where it changes to $\mathrm{n}$ - type conduction. It probably changes to metallic conduction with increasing annealing temperature and crystallinity. 

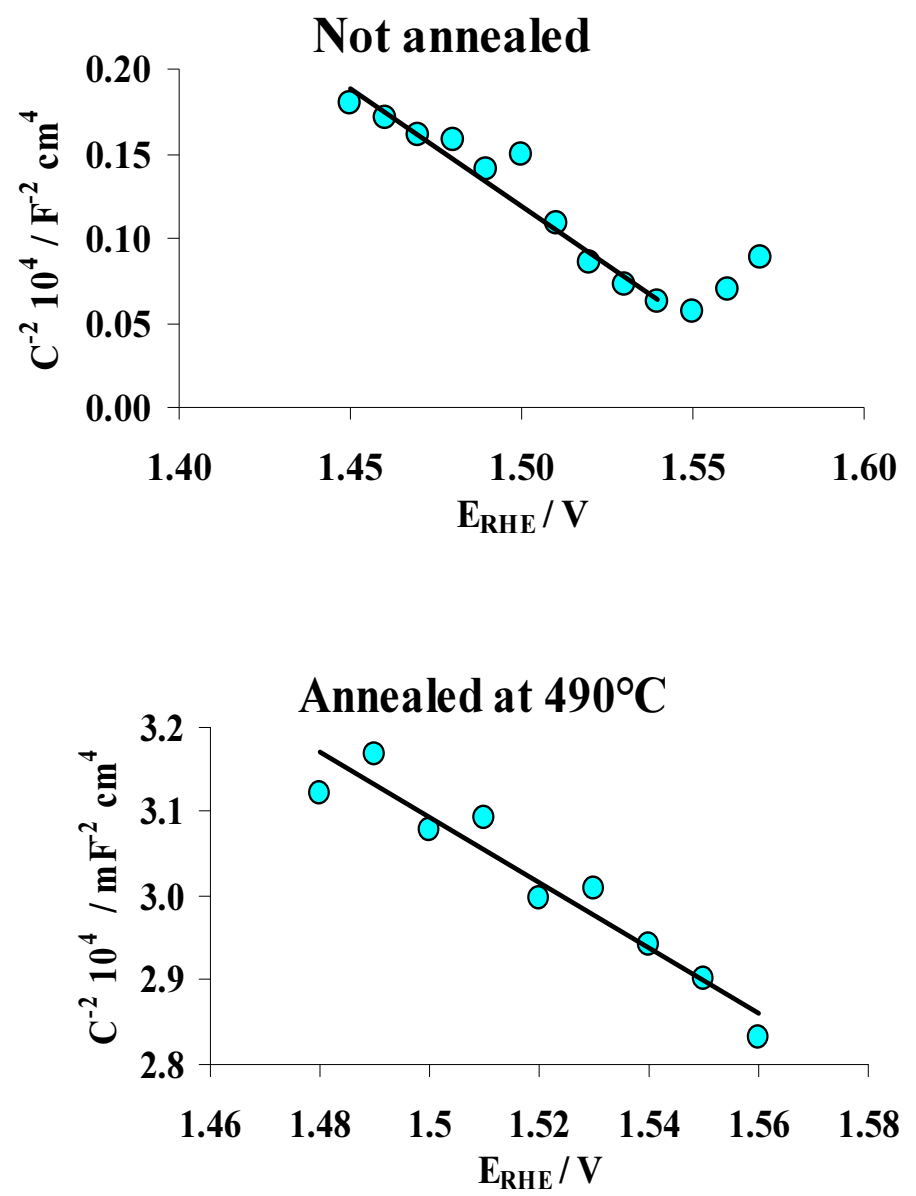

Fig. 4 Mott-Schottky plot for $\mathrm{IrO}_{2}$, not annealed and annealed at $490 \mathrm{C}$ (From ref. 5)

Table 1.Tafel coefficients from polarisation and impedance measurements on $\mathrm{IrO}_{2}$

Anneal.cond. Polarisation curves AC imp.

$\left({ }^{\circ} \mathrm{C}\right) \quad \mathrm{b}_{\mathrm{a}}(\mathrm{mV} / \mathrm{dec}$. $)$ low cds high cds.

\begin{tabular}{llcc}
\hline Non annealed & 36 & 89 & 36 \\
440 & 43 & - & $38 / 95$ \\
490 & 46 & 145 & 42 \\
510 & 47 & 151 & 44 \\
540 & 49 & 146 & 48
\end{tabular}

Both polarisation and impedance data indicate that the second step, the electrochemical oxide step is rate determining at low cds for pure $\mathrm{IrO}_{2}$ whereas the first charge transfer step is rate determining at high cds. This is in accordance with the results of Damjanovic et al (12). 


\section{Effect of additions to $\mathrm{IrO}_{2}$}

$\underline{\text { The } \mathrm{IrO}_{2}} \underline{-\mathrm{SnO}_{2}} \underline{\text { system }}$

Electrocatalytic performance can be divided into two main integral factors:

- $\quad$ Active surface area

- Specific activity of catalyst/electrolyte interface

The active surface area is determined from the voltammetric charge extrapolated to infinite sweep rate, the socalled "outer" charge, which is assumed to be proportional to the area assessible to oxygen evolution. The total charge is found by extrapolating the determined charge to zero sweep rate and includes micropores and other geometries, not available to the electrochemical process above a certain low level. The difference is rather small, however.

Fig. 5 shows the outer anodic charge for binary mixtures of Ir- and Sn-oxides. The active area is rather constant and equivalent to $120-130 \mathrm{mC} \mathrm{cm}^{-2}$ apparent surface area up to $20-30 \mathrm{~mol} \%$ $\mathrm{Sn}$. Then it reduces rather linearly by increasing Sn-amount, to $40 \mathrm{mC} \mathrm{cm}{ }^{-2}$ at 70 and $80 \mathrm{~mol}$ $\%$ Sn-oxide. EXAFS analysis of the local structure showed no evidence that the metal ions were atomically mixed, indicating that this oxide system is not a true solid solution (13). XRDanalysis of $\mathrm{IrO}_{2}-\mathrm{SnO}_{2}$ nanocrystalline powders, however, revealed only a single set of rutile diffraction peaks

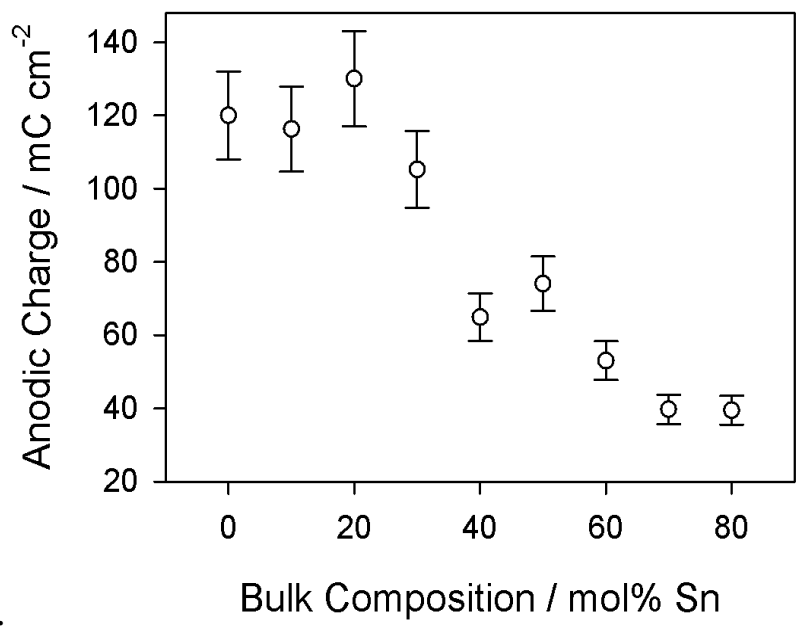

Figure 5. Electrochemically active area of $\operatorname{Ir}_{\mathrm{x}} \mathrm{Sn}_{1-\mathrm{x}} \mathrm{O}_{2}(0.2<\mathrm{x}<1)$

Normalising the current by active area as shown in Fig. 6 indicates that $\mathrm{SnO}_{2}$ has only a slight effect on the specific activity of $\mathrm{IrO}_{2}$ at low cds. The current was normalised by active area of $\mathrm{IrO}_{2}$ using outer charge determined by voltammetry $(\mathrm{mA} / \mathrm{mC}$ charge $)$, a relation that is analogeous to the "turnover frequency" used in catalysis literature. This means that the potential at a normalised current density represents a measure of true specific electrocatalytic activity of the electrode surface. Fig. 6 shows that until about $40 \%$ Sn additions only reduce active area. At higher tin contents the activity decreases with $\mathrm{Sn}$ addition.

The effect of composition on the total I/E- curve is shown in Fig. 7. The effect of Sn-additions are low up to $60 \% \mathrm{SnO}_{2}$ at cds $<100 \mathrm{~mA} / \mathrm{cm}^{2}$. At higher cds the effect is considerable and at $80 \% \mathrm{SnO}_{2}$ it is significant in the whole cd-range. 


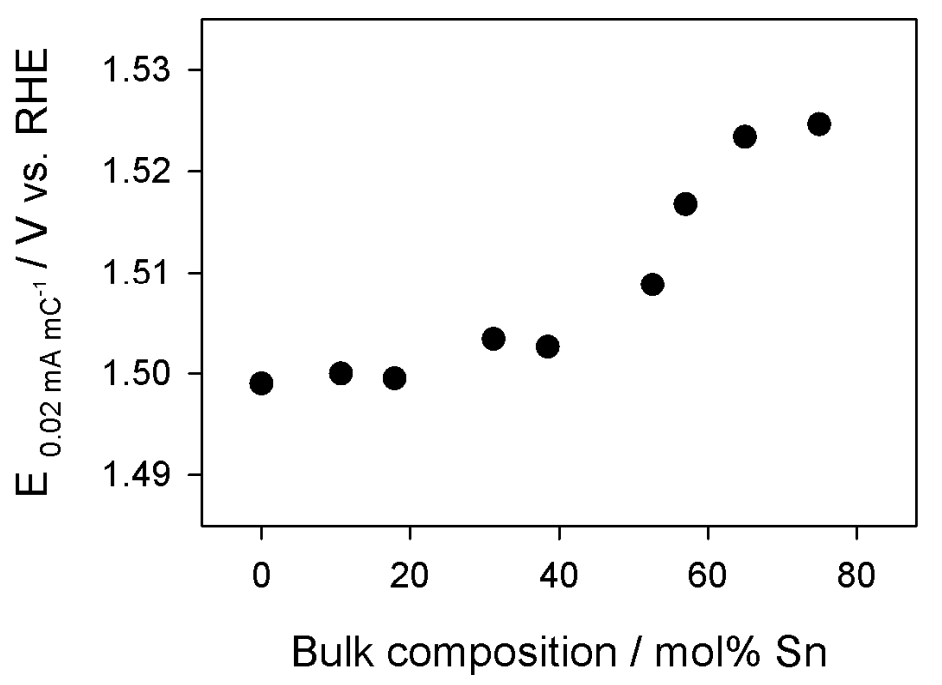

Fig.6 Specific activity of $\operatorname{Ir}_{\mathrm{X}} \mathrm{Sn}_{1-\mathrm{x}} \mathrm{O}_{2}(0.2<\mathrm{x}<0.8)$ (from ref. 9)

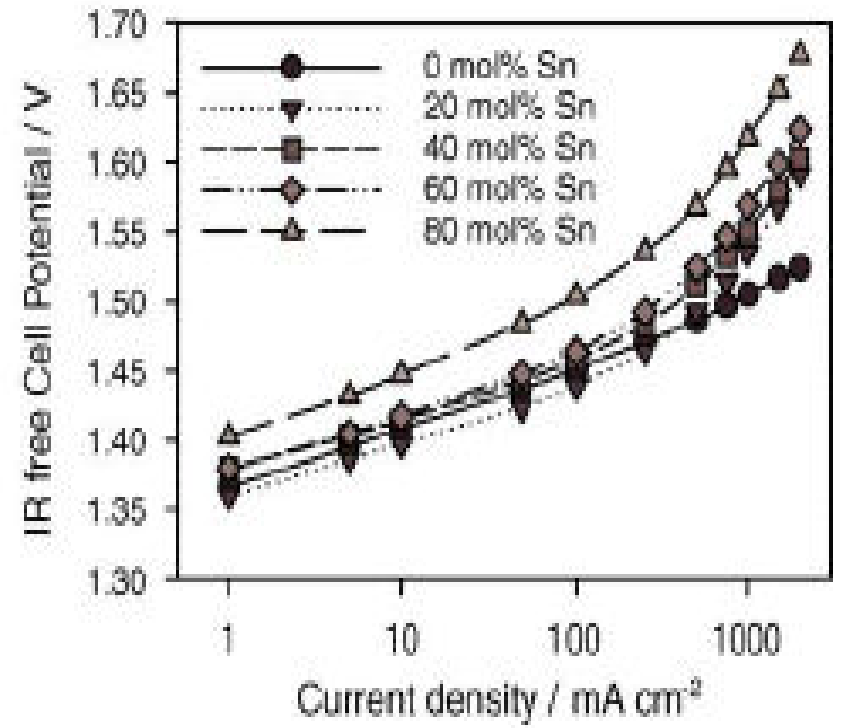

Fig. 7 IR-corrected cell cd/voltage -curves for $\mathrm{IrO}_{2}-\mathrm{SnO}_{2}$-anodes in PEM FC as function of composition at $80{ }^{\circ} \mathrm{C}$ (from ref. 9)

\section{Mechanism of the oxygen evolution process}

$\underline{\mathrm{IrO}_{2}} \underline{\underline{\mathrm{SnO}}} \underline{\mathrm{Sn}_{2}} \underline{\text { system }}$

Based on cd-potential curves as in Fig. 7, Tafel slopes of 30 to $40 \mathrm{mV} /$ decade have been calculated for an Ir-Sn-Oxide electrode in a PEM electrolysis cell. Data for the Tafel slopes from Fig 8 were obtained by very slowly reducing the temperature from $90^{\circ}$ to $25^{\circ} \mathrm{C}$. The resulting Tafel gradients shown in Fig. 8 indicate that that the second step in the total oxygen evolution process is rate determining. The results also show that it is difficult to distinguish between the two proposed paths, the Oxide path ( $2 \mathrm{a}$ in the mechanism), with a Tafel slope of $\mathrm{R}^{\prime} \mathrm{T} / 2 \mathrm{~F}$ and the electrochemical Oxide path ( $2 \mathrm{~b}$ in the mechanism), with a slope of 
$\mathrm{R}^{\mathrm{T}} \mathrm{T} /(1+\alpha) \mathrm{F}$. The figure probably shows that both processes take place in parallel with individual and similar rates depending on local composition and structure of the surface.

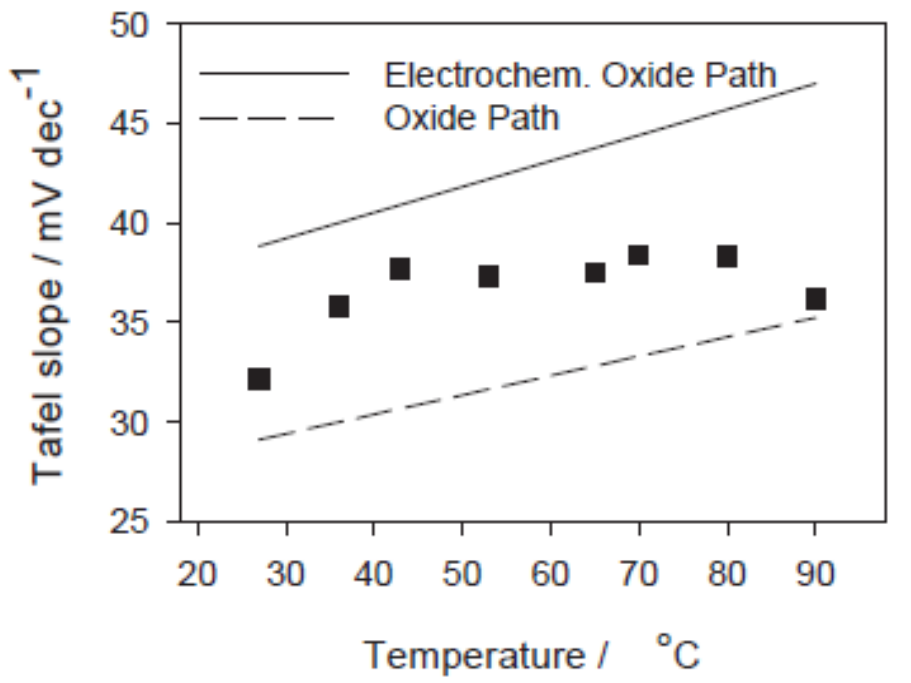

Fig. 8 Tafel slopes vs. temperature on $\mathrm{IrO}_{2}-\mathrm{SnO}_{2}$ anode in PEM WE cell (from ref. 9)

$\underline{\text { The system: } \operatorname{Ir}} \underline{x} \underline{\mathrm{Ru}} \underline{0.5-\mathrm{x}} \underline{\mathrm{Sn}_{0.5}} \underline{\underline{\mathrm{O}}} \underline{\underline{2}}$

As Ir is replaced by Ru the active surface area decreases, as shown in Fig. 9. This seems to be due to a decreasing concentration of noble metals in the surface layer, as also observed by XPS. It is known that $\mathrm{RuO}_{2}$ is more active than $\mathrm{IrO}_{2}$ for oxygen evolution but must be stabilised to maintain suitable lifetime of the electrode.

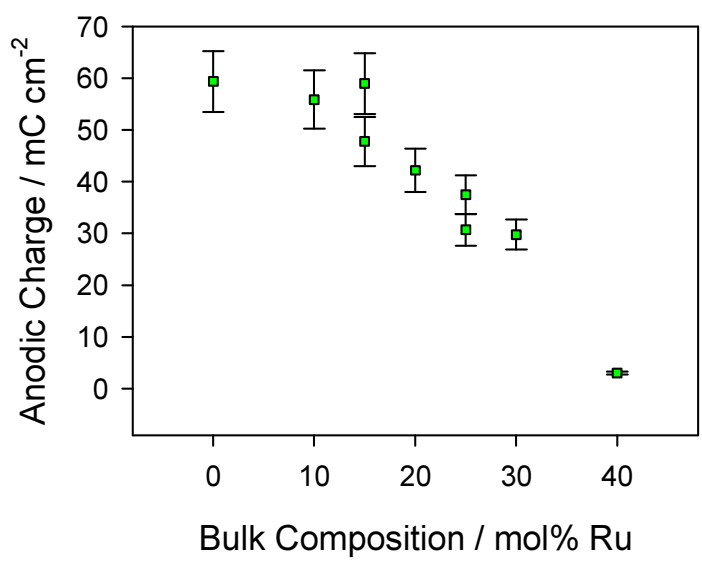

Figure 9. Active area of Ir-Ru-Sn oxide (from ref. 8)

Additions of ruthenium to the binary $\mathrm{IrO}_{2}-\mathrm{SnO}_{2}$ nanocrystalline powders resulted in a more complex particle structure, with $\mathrm{IrO}_{2}-\mathrm{SnO}_{2}$ material coating metallic ruthenium cores. XPS indicated that there was just a minor amount of ruthenium at the particle surface. This could be due to clustering of the metallic ruthenium during the synthesis procedure making a segregated core-shell structure. As Ru replaces Ir, the specific activity, corrected for active area increases, determined as a lowered potential at a low current divided by surface charge as 
$0.02 \mathrm{~mA} / \mathrm{mC}$. The activity increases shown by a potential decrease from 1.51 to $1.48 \mathrm{~V}$ when composition changes from zero Ru-oxide to $40 \%$ Ru-oxide, as shown in Fig. 10.

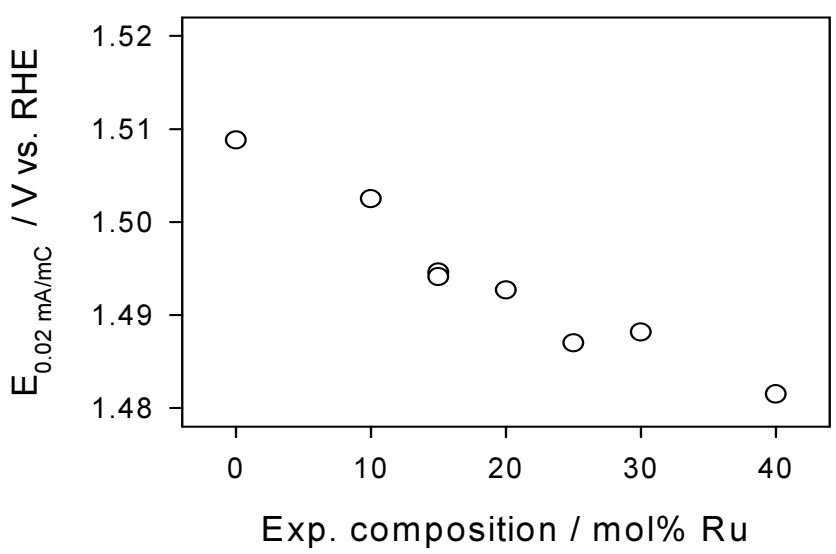

Figure 10. Specific activity of $\operatorname{Ir}_{\mathrm{X}} \mathrm{Ru} 0.5-\mathrm{X} \mathrm{Sn}_{0.5} \mathrm{O}_{2}$ in $0.5 \mathrm{M} \mathrm{H}_{2} \mathrm{SO}_{4}$ (from ref. 8)

These results are obtained despite a very low ruthenium surface concentration and is opposite to the effect of Sn. The core Ru seems to possess an electronic surface effect. A small increase in specific performance determined at constant active surface and at low cds, is observed as Ir is replaced by $\mathrm{Ru}$ up to $20 \%-30 \% \mathrm{Ru}$ and shown in Fig. 11 . Above $30 \%$ the reduced area effect due to addition of Ru gives a small increase in potential. A visible difference between area effects and activity is shown.

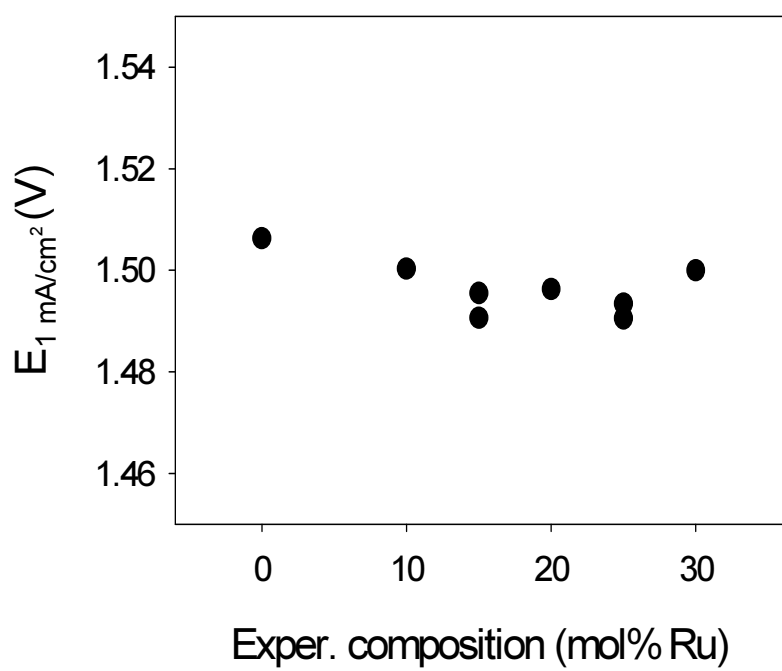

Fig. 11. Potential at $1 \mathrm{~mA} / \mathrm{cm}^{2}$ of Ir-Ru-Sn oxide in $0.5 \mathrm{M} \mathrm{H}_{2} \mathrm{SO}_{4}$

\section{Mechanism of Anode process}

In the $\operatorname{Ir}_{\mathrm{x}} \mathrm{Sn}_{(1-\mathrm{x})} \mathrm{O}_{2}$ system the Tafel gradient varies between 36 and $38 \mathrm{mV} /$ decade when $\mathrm{x}$ $>0.2$. At $x=0.2$ the gradient was determined to $42 \mathrm{mV} /$ decade. The kinetic data in the ternary system where $\mathrm{Ru}$ is also added, are shown in table 2 : 
Table 2

Summary of polarisation measurements of $\mathrm{Ir}_{x} \mathrm{Ru}_{0.5-x} \mathrm{Sn}_{0.5} \mathrm{O}_{2}$ in $0.5 \mathrm{M}$

$\mathrm{H}_{2} \mathrm{SO}_{4}$.

\begin{tabular}{lll}
\hline$x$ & $b$ & $E\left(1 \mathrm{mAcm}^{-2}\right)$ \\
\cline { 2 - 3 } & $(\mathrm{mV} / \mathrm{dec})$ & $(V$ vs. RHE $)$ \\
\hline 0.5 & 35.5 & 1.522 \\
0.4 & 43.0 & 1.500 \\
0.35 & 45.3 & 1.496 \\
0.3 & 45.2 & 1.496 \\
0.25 & 43.9 & 1.493 \\
0.2 & 43.4 & 1.500 \\
0.1 & 83 & - \\
\hline
\end{tabular}

These results indicate that the second step in the oxygen evolution process is rate determining at most conditions with the oxide path determining in the binary Ir-Sn system with a Tafel gradient of R'T/2F, and perhaps the parallel electrochemical oxide path in the ternary system including $\mathrm{Ru}$, with a gradient of $\mathrm{R}^{\prime} \mathrm{T} /(1+\alpha \mathrm{F})$. In the ternary system with $40 \mathrm{~mol} \% \mathrm{Ru}$-oxide and $10 \mathrm{~mol} \%$ Ir-oxide the Tafel gradient increases to $83 \mathrm{mV} /$ decade. This could mean that tha primary charge transfer process with a Tafel gradient of $\mathrm{R}^{\prime} \mathrm{T} / \alpha \mathrm{F}$ becomes rate determining.

The Ir-Ru-Ta-Oxide system

As an alternative to Sn-oxide, Ta-oxide has been added to Ir-Ru-oxide. Compared to Sn-oxide Ta-oxide has no rutile structure. The effect of Ru-oxide additions on the anodic charge, which is assumed to be directly proportional to the electrochemically active area, is shown in Fig. 12 in the system Ir-Ru-Ta-oxide, with $2 \mathrm{mg} / \mathrm{cm}^{2}$ catalyst at the electrode interface. When $20 \%$ $\mathrm{Ru}$-oxide is added the active area increases from 200 to $250 \mathrm{mC} \mathrm{cm}^{-2}$. Higher additions, above $40 \%$ Ta-oxide reduce the charge to about $20 \%$ of this value at $60 \%$ Ru-oxide, mostly because of formation of larger crystallites.

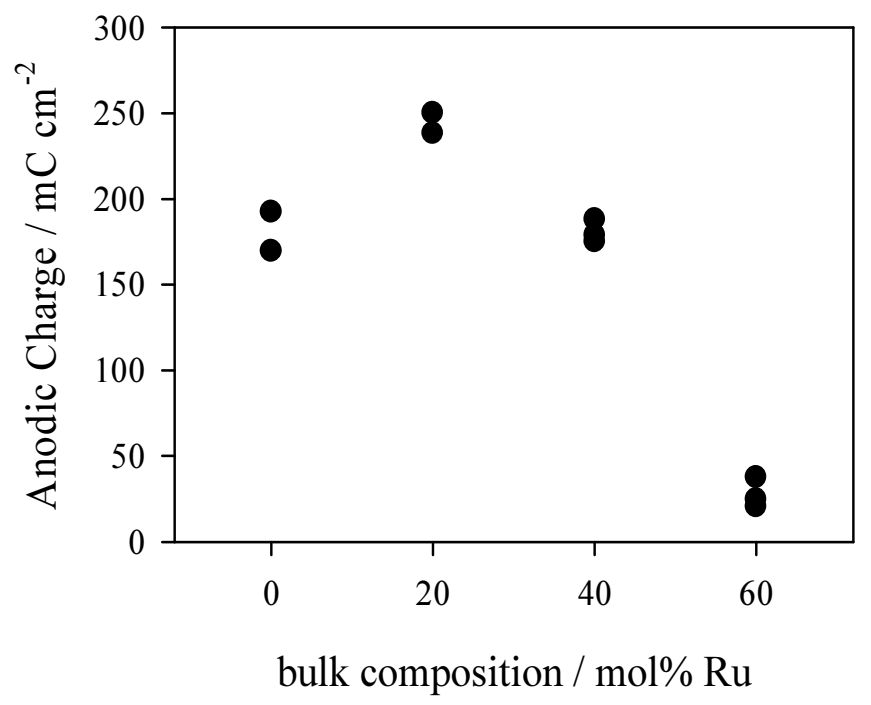

Fig. 12 Electrochemically active area in $0.5 \mathrm{M} \mathrm{H}_{2} \mathrm{SO}_{4}$ - Ir-Ru-Ta oxides with $20 \mathrm{~mol} \% \mathrm{Ta}$ 


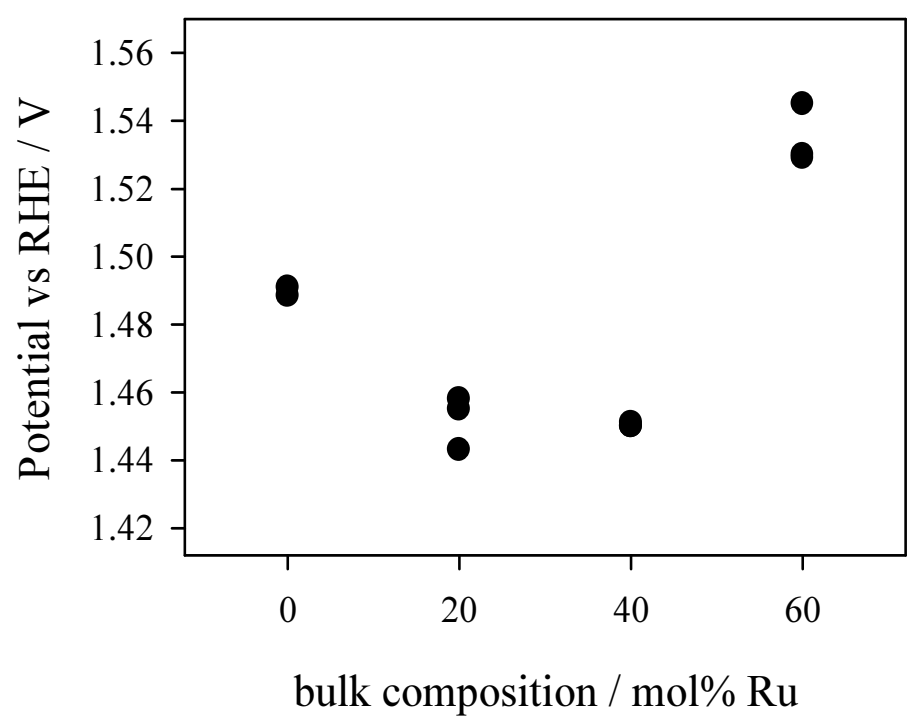

Fig. 13 Potential at cd $1 \mathrm{~mA} / \mathrm{cm}^{2}$ in $0.5 \mathrm{M} \mathrm{H}_{2} \mathrm{SO}_{4}$ - Ir-Ru-Ta oxides with $20 \mathrm{~mol} \% \mathrm{Ta}$ Despite the active area, determined as anodic charge, is rather constant up to $40 \mathrm{~mol} \% \mathrm{Ru}-$ oxide the potential is lowered by $50 \mathrm{mV}$ in the same concentration range.

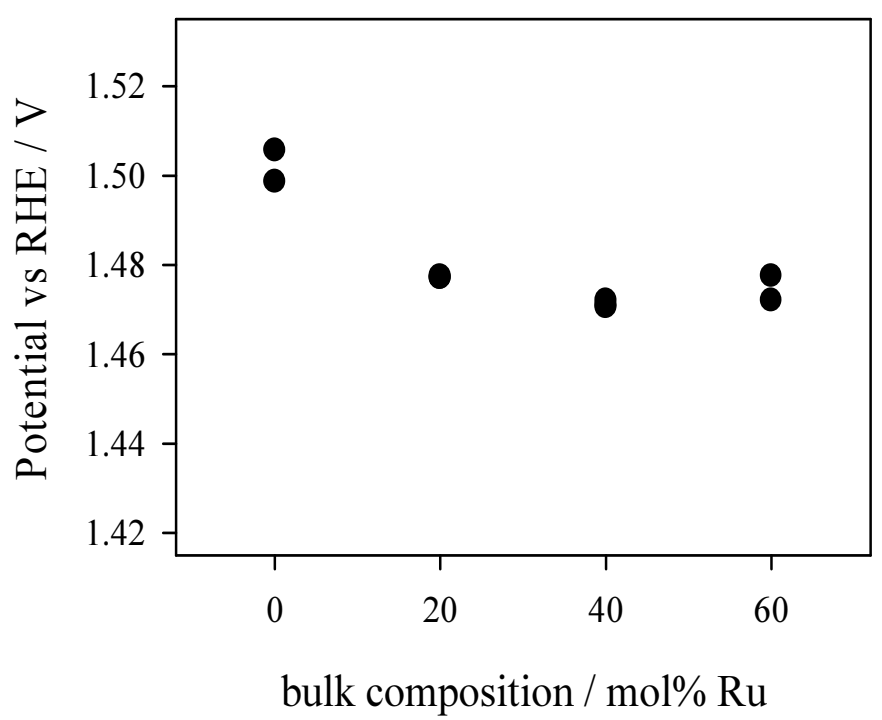

Fig. 14. Specific activity of Ir-Ru-Ta oxides with $20 \mathrm{~mol} \%$ Ta in $0.5 \mathrm{M} \mathrm{H}_{2} \mathrm{SO}_{4}$, potential at $0.02 \mathrm{~A} /$ Coul.

As shown in the ternary system with Ir-Ru-Sn (Fig. 11) the system with Ta also exhibits a shallow minimum in potential at about $40 \%$ Ru-oxide, as shown in Fig. 14. This is made visible by normalising the current density to active area, measured as surface charge. 
Fig 15 shows the obtained Tafel slopes for the ternary system with Ir-oxide varying from 10 to $80 \%$, with Ru-oxide up to $60 \%$ and Ta-oxide up to $30 \%$. In systems with a majority concentration of Ir-oxide the Tafel gradient is low and varies around $40 \mathrm{mV} /$ decade showing as rds the second step of formation of an adsorbed $\mathrm{S}-\mathrm{O}$ species where $\mathrm{S}$ is an active site. When adding $\mathrm{Ru}$ to $50 \%$ the slope is increased if minimum $10 \%$ of $\mathrm{Ta}$ is added simultaneously.

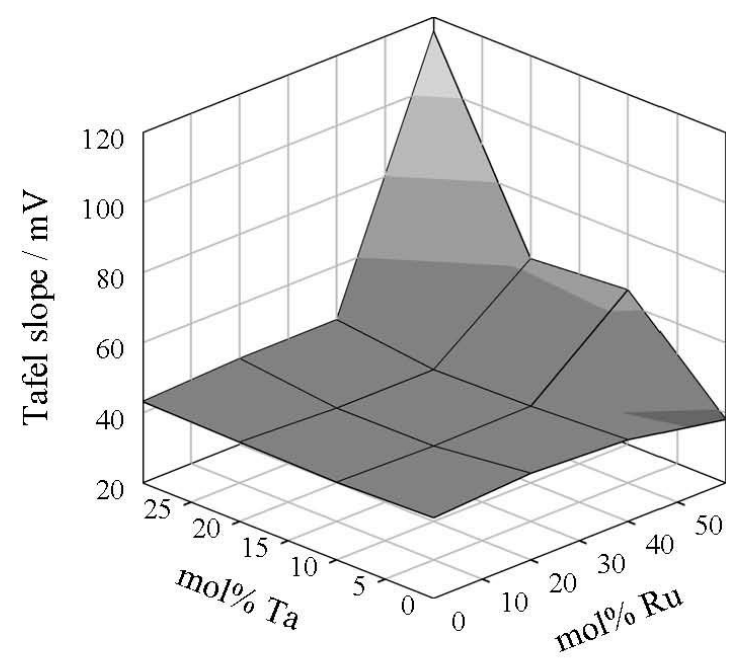

Fig. 15. Tafel slopes of Ir-Ru -Ta oxides in $0.5 \mathrm{M} \mathrm{H}_{2} \mathrm{SO}$

Additions of 10 and $20 \%$ Ta-oxide, increases the gradient to $65-70 \mathrm{mV} / \mathrm{decade}$. When adding $30 \%$ Ta-oxide and $60 \% \mathrm{Ru}$-oxide the gradient raises to $120 \mathrm{mV} /$ decade, pointing to the first charge transfer step as rate determining. Such high gradients were found also by Damjanovic et al (12) on preoxidised Ir and Rh in perchloric acid solutions and at high cds.

Maximum obtained performance in PEM Water Electrolysis Laboratory Cell

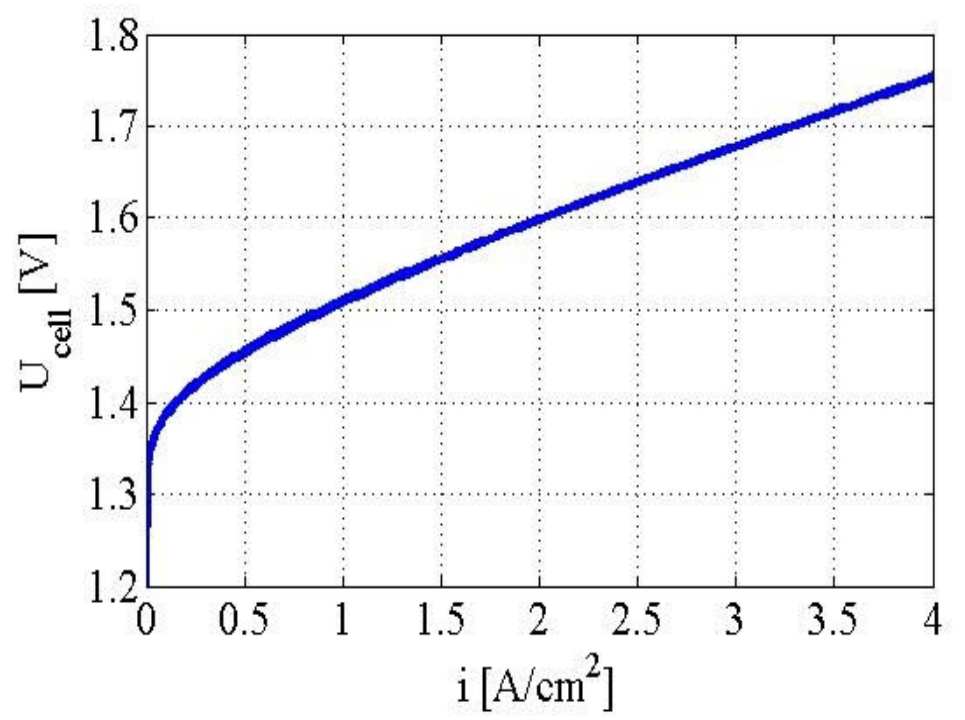

Fig. 16. Maximum performance obtained in laboratory PEM cell 
A polarisation curve with maximum performance is shown in Fig. 16.

This very high performance was observed in a cell with the following characteristics:

- Ti-backing

- Membrane: Nafion

- Cathode: $2.5 \mathrm{mg} / \mathrm{cm}^{2}$ Pt-black sprayed on membrane

- Anode: $2.5 \mathrm{mg} / \mathrm{cm}^{2} \mathrm{IrO}_{2}-\mathrm{RuO}_{2} 70 / 30$, calcined at $490{ }^{\circ} \mathrm{C}$, sprayed on membrane

- Crystallite size of $\mathrm{IrO}_{2} / \mathrm{RuO}_{2}$ about $10 \mathrm{~nm}$

- Temperature: $80^{\circ} \mathrm{C}$

Such high performance depends on very well optimised contacts between all parts in the cell. One should observe that the slope of the curve is decreasing by increasing cd up to 2.5 to 3 $\mathrm{A} / \mathrm{cm}^{2}$, indicating charge transfer control. Increasing cd further, the slope becomes linear with cd, which means resistance control. No transport control was observed.

\section{Effect of Sulfate ions}

Much of the measurements were done in sulfuric acid solutions, for simplicity and for having an anion mimicing the Nafion system. It is well known, however, that sulfate ions adsorp much stronger than Nafion, especially to metallic but also to oxidic interfaces, reducing the active area. To investigate this difference anodic charge determinations were performed for the binary Ir-Sn-oxide in both systems, in $0.5 \mathrm{M} \mathrm{H}_{2} \mathrm{SO}_{4}$ solution and with PEM membrane. The results are shown in Fig. 17.

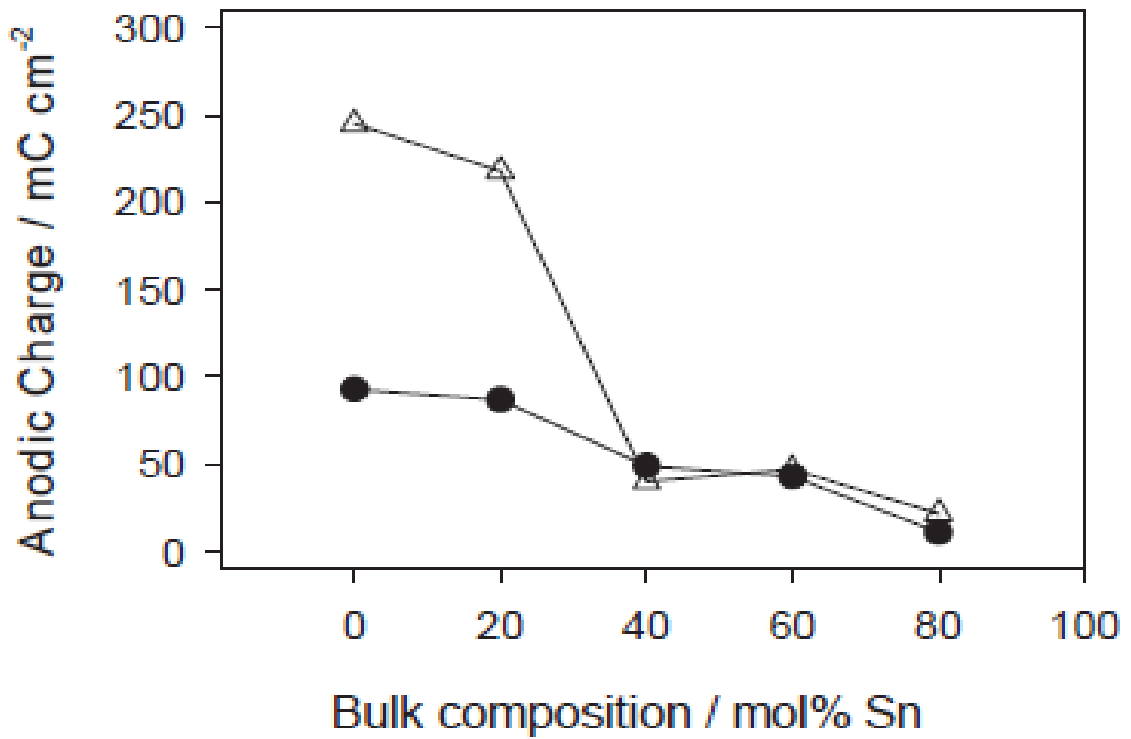

Fig. 17. Outer charge in PEM Cell $(\Delta)$ and in $0.5 \mathrm{M} \mathrm{H}_{2} \mathrm{SO}_{4}(\bullet)$ (from ref. 9)

At high concentrations of active component there is a large difference in anodic charge and corresponding active area, which is more than twice as high in the PEM-system as in sulfuric acid, both with pure Ir-oxide and with 20 mol \% Sn-oxide. At 40 to $80 \%$ of Sn-oxide, however, the charge is exactly the same and considerably lower. This means that we have to be careful in comparing results with PEM and sulfuric acid electrolytes, especially in systems 
with high contents of active component. This means that the sulfate ion adsorb at active surface points partly blocking these.

\section{Discussion and Conclusions}

Ir-oxide is the primary choice as an oxidic material for an oxygen evolving anode. It has a very high surface area, a high catalytic activity and a high stability.Additions of Ru-oxide increases the specific catalytic activity up to $30-40 \%$ Ru-oxide content, when related to a specific low cd at a determined active surface. At higher contents the active specific surface decreases considerably due to a large increase in the crystallite/particle size and reduction in active area. This reduces the total performance.

It seems that $\mathrm{RuO}_{2}$ segregates to the core of the particles from the beginning. If this is due to a faster deposition because of the higher oxidation tendency or if it is due to differences in surface energy is difficult to say. By heat treatment and time Ru seems to move to the surface. This means that catalysts of this system could depend on thermal history.

The rate determining step seems to be the second step in the generally proposed mechanism: a parallel path between a chemical and an electrochemical formation of an adsorbed and unstable S-O intermediate. At high Ru-oxide content the Tafel slope increases, which could mean that the first charge transfer process becomes rate determining with a Tafel gradient of $\mathrm{R}^{\prime} \mathrm{T} / \alpha \mathrm{F}$ amounting to potential/cd slopes above $100 \mathrm{mV} /$ decade. This is very negative for the total cell potential and the energy efficiency at high cds. Modest additions, to $30-40 \%$ are beneficial both for material stability and energy efficiency.

Addition of Sn-oxide decreases active surface but has small effects on specific electrocatalytic performance at contents lower than $40 \%$ but is detrimental at higher contents. Ta-oxide seems to change the rate determining step resulting in a high Tafel slope if simultaneously adding high amounts of Ru-oxide. This could be due to a stability change of the oxide.

Current densities up to $4 \mathrm{Acm}^{-2}$ are obtained without any transport limitation, in a system with an $\mathrm{IrO}_{2}-\mathrm{RuO}_{2}$ anode (70-30 \%) and a Pt cathode.

\section{References}

1) S. Trasatti, J. Electroanal. Chem. 111, (1980) 125-131

2) S. Trasatti, Electrochim. Acta (1984) 1503-1512

3) J. Rossmeisl, Z.-W.Qu, H. Zhu, G.-J. Kroes and J. K. Nørskov, J. Electroanal. Chem. 607 (2007) 83-89

4) E. Rasten, G. Hagen, R. Tunold, Proc. Electrochem Soc. 23 (2001) 151

5) E. Rasten, G. Hagen, R. Tunold, Electrochim. Acta 48 (2003) 3945

6) A. Marshall, B. Børresen, G. Hagen, M. Tsypkin, R. Tunold, Mater. Chem. Phys. 94 (20 05) 226-232

7) A. Marshall, B. Børresen, G. Hagen, M. Tsypkin, R. Tunold, J.New Mater.Electrochem. Syst. 7 (2004) 197

8) A.Marshall, B. Børresen, G.Hagen, M. Tsypkin, R. Tunold, Energy 32 (2007) 431

9) A. Marshall, B. Børresen, G. Hagen, M. Tsypkin and R. Tunold, Electrochim. Acta, 51 (2006) 3161

10) A. Marshall, B. Børresen, G.Hagen, S.Sunde, M.Tsypkin, R.Tunold, Russian J.of Electrochemistry 42( 2006) 1134

11) A. T. Marshall, S. Sunde, M. Tsypkin R. Tunold, Int. J. Hydrogen Energy, 32 (2007) 431

12) A. Damjanovic, A. Day and J.O'M. Bockris, J. Electrochem. Soc. 113 (1966) 739

13) S. Ardizzone, G. Fregonara, S. Trasatti, Electrochim. Acta 35 (1990) 263 
14) A. Marshall, PhD-thesis 2005:96 NTNU, Trondheim Norway 